\title{
A series of noninvasive evaluations for bilateral adrenal tumor
}

\author{
Kenji Hirata $\cdot$ Kouzou Kubo
}

Received: 22 January 2013 / Accepted: 21 March 2013 /Published online: 30 April 2013

(C) Springer-Verlag Berlin Heidelberg 2013

We present an educational case of bilateral adrenal tumor. A 52year-old woman underwent abdominal ultrasonography for screening purposes, which detected bilateral adrenal tumor. On non-contrast-enhanced CT, the left adrenal tumor had a lowdensity area indicating a fatty component (a). Contrast-enhanced CT revealed central necrosis in the right adrenal tumor (b). T2weighted MR imaging showed that the right tumor had high intensity (c). The left tumor appeared with lower intensity on inphase MR imaging (d) compared to out-of-phase MR imaging (e), indicating a fatty component. ${ }^{123}$ I-metaiodobenzylguanidine (MIBG) highly accumulated in the right tumor with preserved physiological uptake in the left tumor (f). The left tumor showed high uptake of ${ }^{131} \mathrm{I}$-adosterol with no accumulation in the right tumor (g). These results of scintigraphy, consistent with CT and MR findings, suggested that the left tumor was an adrenocortical adenoma and that the right tumor was a pheochromocytoma [1]. Laboratory tests revealed elevated urine metanephrines but normal corticosteroids.

The patient underwent laparoscopic right total adrenalectomy. The right tumor was pathologically diagnosed as a pheochromocytoma with no malignancy. The left tumor was not resected.

Surgery is the primary treatment for pheochromocytoma [2]. In contrast, operation is not recommended for hormonally inactive adrenocortical adenoma less than $4 \mathrm{~cm}$ in diameter [3]. This patient had bilateral adrenal tumors, which confused the diagnosis and treatment planning because pheochromocytoma occasionally involves bilateral adrenal glands, especially in multiple endocrine neoplasia [4]. A thorough series of

\footnotetext{
K. Hirata $(\bowtie)$

Department of Nuclear Medicine, Graduate School of Medicine, Hokkaido University,

Kita 15, Nishi 7, Kita-Ku, Sapporo, Japan

e-mail:khirata@med.hokudai.ac.jp

K. Kubo

Department of Radiology, Tomakomai City Hospital,

5-20, Shimizu-cho 1, Tomakomai, Japan
}

noninvasive imaging techniques consisting of CT, MRI, and dual adrenal scintigraphy avoided unnecessary and invasive bilateral tumorectomy and thus prevented adrenal dysfunction.

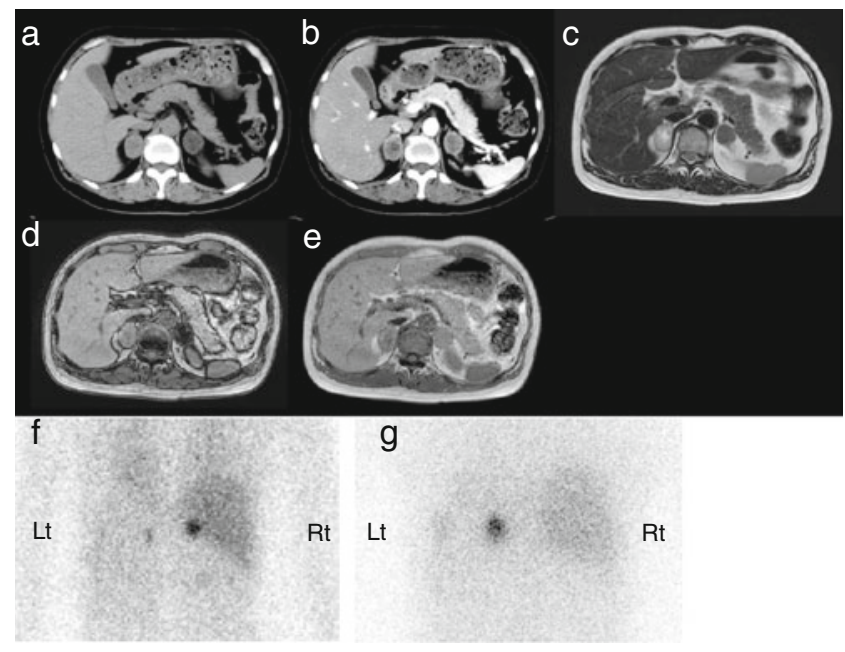

\section{References}

1. Boland GW, Blake MA, Hahn PF, Mayo-Smith WW. Incidental adrenal lesions: principles, techniques, and algorithms for imaging characterization. Radiology 2008;249:756-75. doi:10.1148/ radiol.2493070976.

2. Chen H, Sippel RS, O’Dorisio MS, Vinik AI, Lloyd RV, Pacak K, et al. The North American Neuroendocrine Tumor Society consensus guideline for the diagnosis and management of neuroendocrine tumors: pheochromocytoma, paraganglioma, and medullary thyroid cancer. Pancreas 2010;39:775-83. doi:10.1097/MPA.0b013e3181ebb4f0.

3. Zeiger MA, Thompson GB, Duh QY, Hamrahian AH, Angelos P, Elaraj D, et al. American Association of Clinical Endocrinologists and American Association of Endocrine Surgeons Medical Guidelines for the Management of Adrenal Incidentalomas: executive summary of recommendations. Endocr Pract 2009;15:450-3.

4. Petri BJ, van Eijck CH, de Herder WW, Wagner A, de Krijger RR. Phaeochromocytomas and sympathetic paragangliomas. Br J Surg 2009;96:1381-92. doi:10.1002/bjs.6821. 